\title{
Wealth 2D - An alternative approach to explore wealth effects
}

\author{
Jascha Dräger ${ }^{\mathrm{a},}{ }^{*}$, Klaus Pforr $^{\mathrm{b}}$ \& Nora Müller ${ }^{\mathrm{b}}$ \\ ${ }^{a}$ University of Strathclyde, United Kingdom \\ ${ }^{\mathrm{b}}$ GESIS - Leibniz Institute for the Social Sciences, Germany \\ * Corresponding author: jascha.draeger@web.de, School of Education, University of \\ Strathclyde, 141 St James Rd, Glasgow G4 0LT, United Kingdom
}

This version: January 26, 2023

\begin{abstract}
The analysis of wealth as a predictor variable comes with several conceptual and methodological challenges with important consequences for results. We propose using Generalized Additive Models and jointly evaluating different wealth components to overcome the dependence of wealth effects on implausible assumptions. By conducting a simulation study, we show that our approach describes systematic wealth differences in more detail and overfits less to random variation in the data than standard approaches. We then apply our approach to re-analyze wealth gaps in educational attainment in the US. We find that existing research has misclassified which children have the best and the worst educational prospects. Not negative net worth is associated with the worst educational prospects but only the combination of low gross wealth and low debt. The most advantaged group are not only children with high net worth, but all children with high gross wealth independently of the households' amount of gross debt. Our approach can be easily adapted to other outcomesand other wealth components.
\end{abstract}

Key Words: Generalized Additive Models, Simulation, Net Worth, Wealth

Funding: This work was supported by the German Research Foundation (DFG) under Grant No. 403547843.

Acknowledgements: This paper has profited from feedback of the participants of the ISA Forum 2021 in Porto Alegre, the RC 28 Spring Meeting 2021 in Turku, the Conference of the Academy of Sociology Conference 2021 in Leipzig, and the ECSR Annual Conference 2021. We thank Barbara Felderer, Max Thaning, Alejandra Rodríguez Sánchez, and Øyvind Wiborg for helpful comments on earlier drafts. 


\section{Introduction}

Recent research has established wealth as a unique dimension of socio-economic status, working differently from education, occupation, and income (Hällsten and Thaning 2021; Keister and Moller 2000; Killewald, Pfeffer, and Schachner 2017; Skopek 2015; Spilerman 2000). Wealth plays a major role in reproducing intergenerational inequality in various dimensions, including education, income, occupational status, health, or general well-being. Consequently, ignoring wealth effects leads to underestimating the level of intergenerational inequality.

However, the analysis of wealth as a predictor variable in social stratification research includes several conceptual and methodological challenges with important consequences for results (see Killewald et al. 2017) and the perception of which families seem to be advantaged or disadvantaged. In our paper, we discuss two of them: (1) the multidimensional nature of the wealth measure and (2) the non-linearities in the relationship between wealth and any outcome variable of interest (in the following Y) and propose an alternative approach to overcome the second and alleviate the first problem. We also employ a simulation study to evaluate whether our approach discovers the (in observed data unknown) systematic wealth differences in Y. Finally, we showcase the usefulness of our approach by re-analyzing parts of Pfeffer's (2018) work on 'Growing Wealth Gaps in Education'.

\section{Two challenges when studying wealth effects}

\subsection{Wealth as a multidimensional measure}

Wealth is a multidimensional measure consisting of the combination of different forms of all property, assets, and debt that an entity owns. Yet, empirical researchers usually operationalize wealth as a one-dimensional measure, most often net worth (Killewald et al. 2017). We argue that using only net worth as a measure of wealth is too narrow and will hinder researchers from discovering which wealth components drive wealth effects. 
Wealth consists of real assets and financial assets which can be further decomposed as desired. The most striking differentiation in terms of components - that also differentiates wealth from other economic resources like income - is the one between assets and debt, or in other words, between positive and negative wealth. Net worth is the sum of all assets minus the sum of all debt of an entity. The use of net worth is so widespread that newcomers to the field of wealth research may mistakenly assume that wealth is defined as net worth and not that net worth is only one possible measure of wealth. When using net worth, assets and debt are treated as being the same dimension only with opposite signs. However, debt has a very different meaning for individuals and households than being just the opposite of assets (Dew 2007). Instead, when families accumulate wealth by other means than inheritance, gifts, or lottery wins, they usually accumulate both assets and debt simultaneously. For instance, when families buy a house, they will usually have to take a mortgage of a similar value. Thus, the families' net worth will hardly be affected in the short run, although their wealth portfolio has changed dramatically. In other words, the families' wealth has changed dramatically but orthogonal to the families' net worth. As a consequence of these accumulation processes, there is a strong positive correlation between assets and debt (Brown and Taylor 2008).

Debt can indicate economic hardship as well as economic potential (Spilerman 2000). Different amounts of debt can indicate household differences in access to credit, accumulation strategies, tendencies for risk-taking, and possession of knowledge of investment strategies (Dwyer 2018; Fourcade and Healy 2013; Hansen and Toft 2021). Unsecured debt (debt without collaterals) is usually negatively correlated with desirable outcomes like college completion, whereas secured debt (debt with assets as collaterals) is often positively correlated with desirable outcomes (Zhan and Sherraden 2011). Thus, debt only gets its meaning in relation to assets - although not necessarily in the linear relation as assumed by net worth.

In summary, the problem with net worth is that it assigns families with very different wealth portfolios to the same value. That these different portfolios have the same consequences for children's opportunities seems highly unlikely. Let's assume we have two households: household A has zero assets and zero debt and household B has $\$ 500 \mathrm{k}$ 
gross wealth - consisting of a well-located apartment - and $\$ 500 \mathrm{k}$ debt- which is a bank credit to finance the apartment. Thus, both households have a net worth of zero. Nonetheless, based on their different wealth portfolios, we can expect much better outcomes for B than for A. Children may profit much more from their parents' assets than they suffer from their debt. Unlike children in household A, children in household B can benefit from growing up in the stable environment of a self-owned apartment; from living in a peaceful neighborhood which may provide a stimulating environment in terms of cultural and social capital; and are likely to attend similar well-financed schools (e.g., Conley 2001a; Karagiannaki 2017; Pfeffer 2018). Moreover, the gross wealth and debt differences between households A and B may indicate differences in terms of their general economic situation, including creditworthiness.

A second approach in the literature is to use other one-dimensional measures of wealth like gross wealth (e.g., Conley 2001b; Schneider 2011; Wiborg 2017) or asset-to-debt ratios (e.g., Conger et al. 1992). These approaches make different but equally strong assumptions. By measuring wealth as gross wealth, we implicitly assume that all families with the same gross wealth values have, on average, the same outcome, independent of their wealth portfolio and particularly their amount of debt. Although gross wealth is sometimes a better predictor of the intergenerational transmission of advantages than net worth (Wagner, Boertien, and Gørtz 2020), this does not imply that debt can be ignored.

A third approach in the literature is to include both assets and debt (Dew 2007; Hochman and Skopek 2013; Müller, Pforr, and Hochman 2020) or even more wealth components additively in the analysis (e.g., Boen, Keister, and Aronson 2020). This approach is more flexible, but there remain two problems. First, we do not only have to model the effect of multiple components jointly, we also need to interpret them together to learn which wealth portfolios result in the most or least advantageous outcomes. Second, we ignore that the effect of one wealth dimension may depend on the value of another wealth component. In technical terms, we are missing the interaction between wealth components. 
Currently, researchers deal with the problem of the multiple dimensions and components of wealth by checking the robustness of their results to a few other measures of wealth. However, gross wealth and net worth differences have very different implications, and there is no reliable decision rule on which wealth measure gives the more relevant results. ${ }^{1}$

\subsection{Functional form}

Wealth effects are usually considered to be non-linear: Households with little wealth benefit more from an additional unit of wealth than wealthy households (Gibson-Davis and Hill 2021; Killewald et al. 2017). Non-linear wealth effects are mostly implemented in two ways:

First, researchers model non-linear wealth effects by transforming wealth, most commonly, by taking the natural logarithm of net worth. Doing this, researchers assume that every $\log$ unit increase (about a 2.7 -fold increase) in wealth leads to the same change in the outcome (Miller et al. 2021:159). Yet, the natural logarithm is not defined for zero or negative values that are common in the distribution of net worth. In recent years, researchers often used the inverse hyperbolic sine transformation (Friedline, Masa, and Chowa 2015; Pence 2006) for net worth, which behaves similar to the natural logarithm but allows for retaining zero- and negative-valued observations:

$$
\operatorname{IHS}(x)=\frac{\log \left(\theta x+\sqrt{\theta^{2} x^{2}+1}\right)}{\theta}
$$

where $\theta$ is an arbitrary scale parameter with recommended values of $0.0001,0.00003$, and 0.00001 (Pence 2006). When $\theta$ is close to 1 the IHS-transformation resembles the natural logarithm. Alternatively, some researchers use wealth ranks (e.g., Grätz and Wiborg 2020; Hällsten and Pfeffer 2017; Hällsten and Thaning 2018, 2021).

Second, in addition, or alternative to transforming wealth, researchers explicitly specify non-linear associations. They do this by (1) categorizing wealth ( 7 out of the 25 papers that consider wealth as a predictor reviewed in Killewald et al. 2017), (2) including polynomials of wealth in the specification ( 2 out of 25 papers in Killewald et al. 2017), or (3) using splines (4 out of 25 papers in Killewald et al. 2017). 
Within these approaches, the researchers decide in advance how to specify the functional form of their wealth effect. Since it is not clear which specification provides the best fit between wealth and $\mathrm{Y}$ and how complex the specification should be (e.g., how many wealth categories; which order of polynomials; how many and where to place the knots for splines), the currently recommended practice is to experiment with different specifications (Killewald et al. 2017). However, finding the best fitting function involves finding a compromise between describing the functional form in detail and not fitting the functional form to random noise in the data (i.e., the 'biasvariance trade-off'; e.g., Hastie, Tibshirani, and Friedman 2009). For instance, let's assume that the true functional form is that $\mathrm{Y}$ first increases linearly with wealth but decreases for very high values of wealth (potentially through moral hazard for children's outcomes). If we try to fit this unknown function with a linear effect only, we will not find the decrease in Y for very high wealth. Conversely, suppose we fit a complex functional form (e.g., higher-order polynomials). In that case, we may find a more complex association than the true functional form because of random variation in the sample. Based on a too complex association, we may mistakenly infer that households in a certain wealth range fare better than they actually do in the population. This bias-variance trade-off has been rarely considered in research on wealth effects yet.

\section{An alternative approach}

Instead of this tedious and error-prone procedure of experimenting with different measures and specifications, we propose to consider how the joint distribution of any two (or more) relevant dimensions of wealth - in our example, gross wealth (assets) and gross debt - is associated with $\mathrm{Y}$ - in our case educational attainment. In other words, we suggest exploring which groups on the 'surface' defined by their gross wealth and gross debt are advantaged and which groups are disadvantaged with respect to $\mathrm{Y}$ without making the strong homogeneity assumptions discussed above. We focus on assets and debt because they are jointly accumulated and available in most surveys measuring wealth. Moreover, using assets and debt clearly shows how net worth restricts the potential results we can obtain. The same approach can be used to analyze other wealth components, and it can be generalized to more than two wealth 
components. In the latter case, the results will be less straightforward to interpret though.

Moreover, we propose to employ Generalized Additive Models (GAM; Hastie and Tibshirani 1999; Wood 2017) to overcome model specification issues and over-fitting. GAMs are generalized linear models in which Y depends on the additive combination of unknown smoothing functions (and potentially parametric functions) of the predictor variables. Interactions between predictor variables are only considered if explicitly specified. GAMs combine linear mixed models, generalized linear models (McCulloch, Searle, and Neuhaus 2008), and smoothers (Cleveland 1979). In general, GAMs can be described as (Wood 2017:249):

$$
\begin{gathered}
\mathrm{g}(\mu)=\mathbf{Z} \beta+\sum_{j} f_{j}\left(x_{j}\right) \\
\text { with } \mu=\mathrm{E}(\mathrm{Y})
\end{gathered}
$$

and $\mathrm{Y} \sim$ Exponential family $(\mu$, shape parameters),

where $\boldsymbol{Z}$ is a vector of variables that are considered parametrically, $\boldsymbol{\beta}$ is the corresponding vector of parameters, and $f$ is the smoother function of the $j$ variables that are considered non-parametrically $(x)$. On the left-hand side, we have a link function $g(\cdot)$ that connects the dependent variable with the right-hand side. The dependent variable itself follows a distribution from the exponential family. For our analyses, we use the mgcv-package in R (Wood 2017). Smooth functions can be estimated with different spline functions. We use thin plate regression splines, because here we do not have to choose explicit sets of knots (Duchon 1977). The wiggliness of the smooths is penalized for avoiding overfitting. The wiggliness penalties are estimated with a random effect maximum likelihood algorithm.

We propose considering the combination of gross wealth and debt to explore wealth stratification. Thus, we want to evaluate:

$$
\mathrm{g}(\mu)=\mathbf{Z} ß+f(\text { Gross Wealth, Gross Debt })
$$


Here $f$ (Gross Wealth,Gross Debt) is the sum of a thin plate regression spline smoother of gross wealth, a thin plate regression spline smoother of gross debt, and a thin plate tensor product smoother of gross wealth and debt (Wood 2006). The tensor product smoother over gross wealth and gross debt is used to allow for more flexible non-linear interaction terms.

In our application, we consider whether children have reached a certain level of education or not, for example whether they have obtained a BA degree or not:

$$
\operatorname{Pr}(\text { BA Degree })=\frac{\exp (\mathbf{Z} ß+f(\text { Gross Wealth }, \text { Debt }))}{1+\exp (\mathbf{Z} ß+f(\text { Gross Wealth }, \text { Debt }))}
$$

GAMs have important advantages over alternative methods. In contrast to unregularized regression approaches, the complexity of the association between wealth and the outcome of interest is less restricted by the researchers' decisions (e.g., the number of wealth categories). At the same time, unregularized regression approaches do not consider overfitting issues. In contrast to classical Machine Learning approaches like regression trees, GAMs can consider control variables. Regularized regression approaches (i.e., Ridge and Lasso regressions) can fit flexible associations, can include control variables, and can avoid overfitting. However, regularized regression approaches are not helpful with splines specifications because regularizing splines does not change the number and location of knots. Therefore, although regularized regressions with polynomial approximation can successfully regularize the wiggliness part, they are imprecise at the extreme distribution ends.

The flexibility of GAMs comes at the cost of larger standard errors. Moreover, GAMs do not summarize differences by wealth in one or a few regression coefficients. Instead, we can obtain a predicted value for each combination of gross wealth and gross debt and contrast the predicted values of these different combinations.

\section{Data and variables}

First, we will conduct a simulation study (section 5) to test whether our approach describes wealth differences in more detail and makes more accurate cross-validation predictions than the methods currently used to estimate wealth effects. Second, we 
apply our approach to re-analyze wealth stratification in educational attainment in the US (section 6). Both the simulation study and the showcase application are based on the data of the Panel Study of Income Dynamics (2021; PSID) which was also used by Pfeffer (2018). We base the simulation study on real wealth data to have a more realistic distribution of the wealth components. We use the publicly available data and code provided in Pfeffer $(2018)^{2}$ and augment it with the data on wealth components. In the following, we will shortly summarize the data and variables used for Pfeffer's and our analyses. We will focus on our proposed alternative wealth measures.

\subsection{Data and wealth measures in Pfeffer (2018)}

Pfeffer analyzed wealth gaps in the educational attainment of 20- and 25-year-old individuals using the data of the PSID 2017. He included all children of PSID households who were 10-14 years old when parental wealth was measured (1984, 1989, 1994, and 1999) and for whom information about their educational attainment is available at age $20(\mathrm{~N}=5,025)$ or age $25(\mathrm{~N}=4,344)$. Pfeffer analyzes four outcomes: high school graduation, college attendance, college graduation, and college graduation conditional on attendance.

The predictor of interest in his analysis is household net worth, which is derived from the different wealth components measured in the PSID. The PSID assessed nine wealth components in 1984, 1989, and 1994: 1) the value of the main house 2) the net value of farm and business assets, 3) the value of checking and savings accounts, 4) the net value of real estate other than the main home, 5) the value of shares of stock, 6) the net value of vehicles, 7) the value of investments in trusts or estates, bonds, life insurances, 8) the remaining mortgage on the main house, 9) the value of debts other than mortgages (such as credit card and student loans). Additionally, in 1999, private annuities and IRAs were assessed separately rather than jointly with checking and savings accounts. Net worth is the sum of wealth components 1-7 (plus IRAs in 1999) minus the sum of mortgages and other debt (wealth components 8 and 9). Pfeffer inflated all net worth values to $\$ 2015$ and categorized households into quintiles for most of his analyses. The net worth of the lowest quintile ranges between $\$-1278 \mathrm{k}$ and $\$ 5 \mathrm{k}$ and of the top quintile between $\$ 273.4 \mathrm{k}$ and $\$ 26 \mathrm{~m}$. To distinguish wealth effects 
from the effects of other parental SES dimensions, Pfeffer additionally considers permanent household income, parents' highest education, and the socio-economic index score. He further controls the household size, the number of children in the household, the household head's marital state, the mother's age, and the individuals' sex.

Pfeffer reports an almost linear increase in the probability of high school graduation (from $72.8 \%$ in the lowest quintile to $91.1 \%$ in the highest quintile), the probability of college attendance $(21.3 \%$ to $53.3 \%)$, and the probability of obtaining a BA degree $(9.1 \%$ to $53.7 \%)$ over net worth quintiles. Adjusted for covariates, there remains a gap of 6.4 percentage points between the lowest and the highest net worth quintile for high school graduation, 7.2 percentage points for college attendance, and 10.5 percentage points for obtaining a BA degree.

\subsection{Our modifications}

Instead of combining these nine components to net worth, we differentiate between gross wealth and gross debt. We define gross wealth as the sum of the wealth components 1-7 (plus the value of IRAs for children born after 1985). We define gross debt as the sum of mortgages and other debt (wealth components 8 and 9). We transform gross wealth and gross debt using the inverse hyperbolic sine transformation with a scale parameter of $\theta=0.0001$ to start from a smoother association between wealth and Y.

We had to drop three cases from our sample that were included in the net worth measure of Pfeffer (2018), because of missing values in the wealth components. ${ }^{3}$ This leaves us with an analysis sample of $\mathrm{N}=4,341$.

\subsection{Joint distribution of gross wealth and debt}

Figure 1 shows the resulting joint distribution of gross wealth (x-axis) and gross debt (y-axis), which we will use both for the simulation study and the replication of Pfeffer (2018). The distribution of gross wealth and debt are both highly skewed. Gross wealth ranges from $\$ 0$ to about $\$ 26 \mathrm{~m}$, with the $90^{\text {th }}$ percentile possessing around $\$ 640 \mathrm{k}$. The average gross wealth is $\$ 298 \mathrm{k}$ and the median gross wealth is $\$ 144 \mathrm{k}$. The distribution 
of gross debt looks rather similar. Mean gross debt is about $\$ 77 \mathrm{k}$ and median gross debt equals $\$ 36 \mathrm{k}$. About $19 \%$ of households have zero debt, while the most indebted $10 \%$ of the households have more than $\$ 188 \mathrm{k}$ gross debt, and one outlier even reports $\$ 16 \mathrm{~m}$ debt.

Gross wealth and debt are highly correlated. Their Pearson correlation is 0.40 , and their Spearman correlation is 0.73 . Most households are clustered around the main diagonal (close to zero net worth) or to the right of it (larger gross wealth than gross debt).

[Figure 1 about here]

\section{Simulation}

To test whether our new approach performs better in capturing systematic wealth variation in the data as compared to common approaches, we apply a simulation study. In contrast to analyzing observed outcomes, using a simulation study allows us to define the wealth effects. If one of the models we include in our simulation predicts values in a certain wealth range that differ from the pre-defined values in this range, this can unambiguously be defined as a biased prediction.

\subsection{Design of the simulation}

We follow the reporting scheme for simulation studies proposed by Morris, White, and Crowther (2019).

Aims: The aims of the simulation study are 1) to evaluate how well the different combinations of methods, wealth measures, and specifications (see Table 2; in the following referred to as 'combinations') capture the association between wealth and Y in the analysis sample, and 2) to evaluate how well the different combinations can predict $\mathrm{Y}$ in cross-validation.

Cross-validation is a method to approximate the prediction accuracy of a statistical model for new data from the same population. This can be achieved by estimating the model with a random subset of the data (i.e., the 'training data'), predicting the values for the subset of the data that has not been used for estimating the model (i.e., the 'test data') and then calculating the prediction error in the test data (Hastie et al. 2009). We 
use 5-fold cross-validation. Thus, the data is split into five parts. Four of these five parts serve as training data and are used to estimate the model. Their predictions are tested in the remaining fifth part. This is repeated five times until each part has served as test data once. The cross-validation prediction error is then calculated as the average prediction error.

Data-generating mechanisms: We consider four data-generating mechanisms. These are based on the observed values of net worth, gross wealth, and debt in the PSID.

$$
\begin{gathered}
Y_{1}=\text { Net Worth }(\text { IHS transformed; } \theta=0.0001) \\
Y_{2}=\text { Gross Worth }(\text { IHS transformed; } \theta=0.0001) \\
Y_{3}=2 * \text { Gross Wealth }(\text { Rank })-\text { Gross Debt }(\text { Rank }) \\
Y_{4}=\left\{\begin{array}{c}
-2+\text { Gross Debt }(\text { Rank }) \text { if Gross Wealth }<\$ 50,000 \\
0 \text { if } \$ 50,000 \leq \text { Gross Wealth }<\$ 100,000 \\
2-\text { Gross Debt }(\text { Rank }) \text { if Gross Wealth } \geq \$ 100,000
\end{array}\right.
\end{gathered}
$$

Next, $Y_{1}$ to $Y_{4}$ are standardized to have a mean of 0 and a standard deviation of 1 . The resulting true values are displayed in the supplementary materials A. Last, we add $\sqrt{9}$ times normally distributed random noise to the true value and standardize again. Thus, the true value accounts for $10 \%$ of the variance in the noisy variable. We generate data $n_{\text {sim }}=500$ times for all $n_{o b s}=4,341$.

$Y_{1}$ depends only on the net worth of the household and $Y_{2}$ depends only on the gross wealth of the household. These data-generating mechanisms are very parsimonious and should be easily detectable if the correct measure of wealth is used. $Y_{3}$ is a function of the linear combination of gross wealth and gross debt, with gross wealth being twice as important as debt. In the following, we will refer to this data generating mechanism as 'Additive (Ranks)'. This data-generating mechanism is slightly more complex and can already not be fully captured by only using one measure of wealth. We use the ranks of gross wealth and debt to get a functional form that can only be captured by a non-linear association of the original values of gross wealth and debt. The fourth datagenerating mechanism is almost unrealistically complex because it combines threshold effects and interactions. Therefore, we will refer to the fourth data generating 
mechanism as 'Complex Interaction' in the following. For households with little gross wealth, higher debt is associated with larger values in $Y_{4}$. For households with moderate levels of gross wealth, debt is unrelated to $Y_{4}$. For households with high gross wealth, higher debt is associated with smaller values in $Y_{4}$. Unrealistic data-generating mechanisms are helpful in assessing the breaking points of methods (Morris et al. 2019:2078).

Estimand: The estimand of interest for both our research aims is the Mean Squared Error (MSE). It measures how close the predicted values of the different combinations are to the true values of $Y$. Since $Y_{1}$ to $Y_{4}$ are standardized to an SD of 1.00, a MSE of 1.00 indicates that the model does not make better predictions of $Y$ than if we just had ignored wealth and predicted the mean value of $\mathrm{Y}$ for everyone. An MSE of 0.90 indicates that the model captures all the systematic wealth variation in the data and predicts the true value of Y perfectly because $90 \%$ of the variation in $\mathrm{Y}$ is just noise and $10 \%$ systematic variation by wealth.

Methods: For each simulated dataset, we consider 16 different methods which results from the combination of four wealth measures and four different wealth specification (see Table 1). The four considered wealth measures are

1) net worth (methods 1-4),

2) gross wealth (methods 5-8),

3) both gross wealth and debt (methods 9-12),

4) the joint distribution of gross wealth and debt (methods 13-16).

The four wealth specifications are

1) linear specification (methods $1,5,9,13$ ),

2) wealth in quintiles (methods $2,6,10,14$ ),

3) cubic specification (methods $3,7,11,15$ ),

4) non-parametric using GAM (methods 4, 8, 12, 16),

[Table 1 about here] 
Performance measures: On the one hand, we estimate the MSEs for the sample that has been used to estimate the model ('In-sample MSE'). On the other hand, we estimate the MSEs for the prediction accuracy in new data using cross-validation ('Out-ofsample MSE') (e.g., Hastie, Tibshirani, and Friedman 2009).

\subsection{Results of the simulation}

Figure 2 shows the results of the simulation. The colored dots indicate the average MSE over the 500 simulations for the 16 different combinations (on the y-axis). The vertical lines around the colored dots indicate the Monte Carlo 99\% confidence intervals. The left panel shows the in-sample MSEs of the combinations, the right panel the out-ofsample MSEs. The green vertical line indicates the 'target' MSE of 0.90.

Regarding the measure of wealth, we see that most models capture the systematic variance only for some data generating mechanisms but not for others. Models that use net worth (models 1-4) or gross worth (models 5-8) only capture wealth effects well if the data generating mechanism exactly corresponds to this one-dimensional measure of wealth. For instance, if net worth is the data generating mechanism (red squares), we obtain an MSE of 0.90 when measuring wealth as net worth. In contrast, we miss a lot of the systematic wealth differences for any other data-generating mechanism. We only get MSEs of around 0.92 if the data is generated by gross wealth (blue dots) or by an additive combination of gross wealth and debt (green triangles) and an MSE of 0.930.95 if the data was generated by the interaction of gross wealth and gross debt (purple diamonds). Models considering gross wealth and debt in an additive manner (models 9-12) capture wealth effects well if the data generating effect is 'Gross Wealth IHS'. Moreover, these capture more systematic variance if the data generating mechanisms is either 'Additive (Ranks)' or 'Complex Interaction' compared to the models only considering net worth or only gross wealth. Most of the MSEs for these data-generating mechanisms are between 0.905 and 0.92 . Even more systematic variance is captured when considering the joint distribution of gross wealth and debt (models 13-16), particularly for the data generating mechanisms 'Complex Interaction'. Most MSEs for these models are between 0.90-0.91. 
Regarding, the specification of wealth effects, we see that more complex specification, like cubic specifications and the non-parametric effects of GAM, have lower in-sample MSEs than less complex specifications. Overall, the smallest in-sample MSEs over all data generating mechanisms are obtained when the joint distribution of gross wealth and debts are considered, and when using a cubic specification (model 15) or when using GAM (model 16).

Yet, GAM with the interaction of gross wealth and debt predicts outcomes for new data better than the complex GLMs, as indicated by the lower cross-validation MSEs (see right part of Figure 2). The complex GLMs which consider the interaction between gross wealth and debt (models 14 and 15) overfit the data, and have much higher outof-sample MSEs than in-sample MSEs. Their out-of-sample MSEs range between 0.908 and 0.923 . The GAM with the interaction of gross wealth and debt overfits but much less than the complex GLMs. The out-of-sample MSEs of the GAM range from 0.902 to 0.909 .

Taken together, the GAM with the interaction of gross wealth and debt captures most of the systematic wealth variation for all four data-generating mechanisms, giving it an edge over models with more parsimonious measures or wealth specifications. At the same time, the GAM makes a more accurate out-of-sample prediction, giving it an edge over the complex GLMs.

[Figure 2 about here]

\section{Showcase analysis - wealth gaps in educational attainment}

The advantage of GAM with transformed gross wealth and gross debt may only apply to the specific data-generating mechanisms considered in the simulation study. It may not apply to the association between wealth and the outcome of interest in observational data. Moreover, differences in the substantial results derived from the different approaches might be too small to be meaningful. Therefore, we next turn to our showcase analysis, in which we re-analyze the study of Pfeffer (2018) on the association between parental wealth and children's educational attainment in the US. 
Figures 3-5 contrast the predictions of having completed high school, having attended college, and having obtained a BA based on a GLM using net worth quintiles compared to GAM. The colors of the dots indicate the predicted probabilities ranging from children with the worst educational prospects (dark red dots) to children with the best educational prospects (dark green dots). ${ }^{4}$ The exact predicted probabilities and their standard errors are available in supplementary materials B; the underlying regression coefficients of the GLMs and smoothing parameters of the GAMs are available in supplementary materials $\mathrm{C}$.

When using net worth quintiles (upper left part of Figure 3) to evaluate wealth gaps in high school completion, we obtain the common result that children in the lowest net worth quintile have the lowest probability of completing high school (Predicted probability $=80.2 \%$; $\mathrm{SE}=1.6$ ) and children in the highest net worth quintile the highest (Predicted probability $=97.4 \% ; \mathrm{SE}=0.5$ ).

When using GAM instead of quintiles - but sticking to net worth as a measure of wealth (lower left part of Figure 3) - we largely see the same pattern as with net worth quintiles but gain information of differences within net worth quintiles. Children in households with very high net worth, e.g., $\$ 1 \mathrm{~m}$, are even more likely than the other children in the highest net worth quintile to complete high school (Predicted probability: 98.2\%, $\mathrm{SE}=0.5 \%$ ). At the bottom of the net worth distribution, we see that children with high negative net worth have a higher probability to complete high school (e.g., $84.1 \%$ at $\$ 30 \mathrm{k}$ net worth) than children in household with zero or negative net worth (82.8\% at zero net worth).

When using the interaction of gross wealth and debt instead of net worth - but sticking with the specification of quintile effects (upper right part of Figure 3) - we have to revise our picture of the most and the least advantaged children. Children in households in the lowest gross wealth quintile and the lowest debt quintile have by far the lowest predicted probability of completing high school (Predicted probability: 73.2\%, $\mathrm{SE}=0.3 \%$ ). Their probability is even substantially lower than for children in the lowest gross wealth quintile but a higher debt quintile. For instance, the predicted probability of high school completion among children in the lowest gross wealth quintile but the 
second debt quintile is $87.8 \%$ ( $\mathrm{SE}=0.3 \%)$. Children in the fifth gross wealth quintile and the fourth or fifth debt quintile have the highest predicted probability of completing high school (98.7 and $97.9 \%, \mathrm{SE}=0.1 \%$ ). This probability is even higher than for children in households in the same gross wealth quintile but a lower debt quintile.

Yet, when considering the interaction of gross wealth and debt with quintile effects, there remain some problems, namely that some combinations of gross wealth and debts are very sparsely populated (particularly the group of children in household in the lowest gross wealth quintile but the highest debt quintile); the arbitrary threshold between quintile groups; and heterogeneity within quintile groups. When using GAM with the interaction of gross wealth and debt (lower right part of Figure 3) the large contrasts between children at the thresholds of the quintile groups are smoothed. Moreover, there is substantial variation even within the group of children in the lowest gross wealth and lowest debt quintile. Children in household with as little as \$3k gross wealth and zero debt are more than six percentage points more likely to complete high school than children in household with zero gross wealth and debt. Similar patterns emerge for college attendance and obtaining a BA (see Figures 4 and 5).

[Figure 3 about here]

[Figure 4 about here]

[Figure 5 about here]

For all three outcomes, we find two substantial differences in the results of the different methods. First, educational attainment is much stronger determined by wealth when considering the joint distribution of gross wealth and debts than when only considering net worth. The deviance explained by wealth is about one-third larger when considering both gross wealth and debt. In other words, wealth gaps in educational attainment are underestimated when considering net worth only. In contrast, considering wealth in a non-parametric way hardly contributes to the explained deviance.

[Table 2 about here] 
The second and even more consequential difference is that we misclassify which children are (most) advantaged and (most) disadvantaged when using net worth. Not children in households with negative or zero net worth have the worst educational prospects but children in households with zero gross wealth and little to zero debt. The educational prospects of children in this group are substantially worse than the prospects of the (heterogenous) group of children in household with low net wealth.

Moreover, researchers are often interested in the wealth gaps when adjusting for other measures of socio-economic status or potential confounders. Wealth gaps in educational attainment shrink drastically when adjusting for other measures of parental SES and demographics (see supplementary materials D). Regarding high school graduation and colleage attendance, we find the same pattern as for the unadjusted wealth gaps. For obtaining a bachelor's degree, only households gross wealth but not debt seem to be relevant.

\section{Discussion}

Existing research on wealth effects on all kinds of outcomes is restricted by conceptual decisions about how wealth effects may look like. Researchers can only find what their research design allows them to see. By measuring wealth as net worth, researchers make strong and often implicit assumptions about which combinations of wealth components will result on average in similar outcomes. Likewise, the scope of results they can obtain is restricted.

We proposed to explore wealth effects on the surface of gross wealth $\times$ gross debt using Generalized Additive Models (GAM) to overcome the problem of the non-linearity of wealth effects and diminish the challenge of selecting the relevant wealth measure(s). In a simulation study, we showed that our suggested approach performs better in discovering systematic wealth differences than parsimonious parametric models and, at the same time, overfits less and produces more generalizable results than complex parametric models.

Applying our approach to wealth gaps in educational attainment, we found that we must partly revise our understanding of how wealth shapes children's educational 
opportunities. Results based on our approach showed substantial systematic variation in educational attainment among children in households with the same net worth value but different combinations of gross wealth and debt. Most importantly, our approach showed that children from households with similar and high values of gross wealth and gross debt belong to the most privileged children in terms of educational prospects, while previous research falsely assigned them to the least privileged group. At the same time, children with low net wealth are most disadvantaged if they live in households with neither assets nor debt. Children in households with low assets combined with higher amounts of debt - who so far have been falsely identified as belonging to the most disadvantaged group - fare similarly well as children from households with medium amounts of assets.

Studying wealth stratification on the surface of gross wealth $\times$ gross debt using GAMs can also deepen our theoretical understanding of the mechanisms underlying the relationship studied. Our analyses on wealth effects on educational outcomes in the US showed that in the middle and the top of the wealth distribution, gross wealth is a better predictor of obtaining a college degree than net worth. As the largest asset and debt components of households in the middle and the top of the wealth distribution are real estate (in the middle, this is mostly owner-occupied housing, at the top, other real estate) and mortgages on them, we repeated our analyses on the surface of gross housing wealth $\times$ mortgages. We found that the value of the house is much more relevant for obtaining a college degree than the remaining mortgage, which is in line with the findings of Boen, Keister, and Aronson (2020) and Wagner et al. (2020). This could mean that children benefit from stable housing conditions and a good neighborhood, independent of how much mortgage debt their parents owe. Our findings that debt is a disadvantage only for households with little or no assets while for households with medium or large wealth, high debt is not related to educational attainment might indicate that another factor causes the observed differences: access to credit. High debt might be an indicator of access to credit, while no debt may indicate low creditworthiness. Also, it might indicate two different types of debt underlying these relationships, namely productive or wealth-generating debt (i.e., mostly mortgage debt) as compared to unproductive or consumption debt (e.g., credit card debt; Hiilamo 
2020) or to different kinds of indebtedness, such as over- and under-indebtedness (Betti et al. 2007) or secured and unsecured loan. As to the later ones, Zhan and Sherraden (2011) found college completion to be positively affected by secured loan and negatively by unsecured loan. Cai et al. (2021) found secured debt to be related to other dimensions of well-being as unsecured debt. From a conceptual perspective, Hansen and Toft (2021) refer to a undertheorizing of debt in social stratification research in general and in the analysis of social classes in particular. They state that raising debt can be a strategy to accumulate wealth that requires access to credit. Debt might even constitute an additional dimension of social inequality, reinforcing existing social inequalities. Credit institutes are likely to facilitate debt-based accumulation by the already advantaged groups while providing high-interest consumercredit to the already disadvantaged ones (Hansen and Toft 2021).

While our approach avoids several pitfalls in analyzing wealth effects, it also has some limitations. Most importantly, the choice of the scale parameter in the IHS transformation can affect the results (Aihounton and Hennigsen 2020) even when using GAM. Therefore, researchers still have to check their results' robustness to the scale parameter choice. The results of our re-analysis of Pfeffer (2018) are robust when using the other recommended scale parameters of 0.00003 and 0.00001 (Pence 2006). Second, there may not only be large heterogeneities between households with the same net worth but also differences between households with similar amounts of gross wealth and gross debt but different wealth portfolios, i.e., different types of assets (e.g., homeownership wealth, other real estate, stocks, bonds, business assets) and debt (e.g., mortgage, consumption debt). GAMs can also be applied to three or more wealth components. However, the interpretation of these models becomes very difficult when considering more than two components and their interactions.

Based on our findings, what are our suggestions for social stratification scholars studying wealth as an independent variable? We recommend analyzing differences on the surface of gross wealth $\times$ gross debt using GAM as a default first step whenever researchers consider combining assets and debt to net worth. If the resulting pattern aligns with the net worth assumptions, this analysis justifies using net worth. Otherwise, the resulting pattern may suggest the use of other one-dimensional measures 
of wealth or suggest to jointly model assets and debt. In the same vain, the resulting pattern may justify a certain parametric specification of wealth effects. Analyzing differences on the surface of gross wealth $\times$ gross debt using GAM can replace the standard procedure to check the robustness of wealth effects to several one-dimensional wealth measures.

Wealth has to be measured with sufficient detail to check how wealth should be measured and if and how specific wealth components should be combined into a single measure. Therefore, we recommend surveys that cover wealth to separately ask at least for assets and debt, instead of only asking for net worth. First, our paper supports the claim that net worth is not always the most relevant measure of wealth. Second, to report net worth, individuals have to subtract their debt from their assets, which means they have to look up or calculate these measures anyway.

Our approach is easily applicable using the R-package mgcv (Wood 2017) and can be used for most outcomes of interest. Applying our approach may challenge existing results also for other outcome variables affected by wealth such as health, or general well-being. On the downside, our approach is likely to make subsequent analyses more complicated. This comes, however, at the virtue of being more likely to correctly identify advantaged and disadvantaged groups. Only if such groups are identified correctly, policymakers can install targeted measures to efficiently reduce potential inequalities. 


\section{Endnotes}

1. Importantly, we do not solve this problem here, but intentionally devoted ourselves to decompose the wealth measure most frequently used in the literature, namely net worth, into its positive (assets) and negative (debts) components to show what we miss if we assign entities with very different portfolios of assets and debt to the same value of wealth (net worth). To solve this problem, we would have to include every (available) asset component - in our showcase analysis with PSID data, nine - including all possible interaction between these components in our model. While this is possible, it does not correspond to our central research interest here. Rather, we understand this as an avenue for future research.

2. The data are available from: https://simba.isr.umich.edu/data/data.aspx. The replication files for the analysis of Pfeffer (2018) are available from: https://www.openicpsr.org/openicpsr/project/101105/version/V2/view.

3. Composite measures of wealth were imputed in PSID, but not all wealth components. Unlike Pfeffer (2018), we lose these cases with missing values in wealth components since we need full information on the wealth components to separately measure gross wealth and debt.

4. If all relevant confounders of the relationship are included in the model, the difference in the predicted probability of any contrast of values on gross wealth and assets can be interpreted as 'effect' of having this combination of gross wealth and debt instead of the other combination. 


\section{References}

Aihounton, Ghislain B. D., and Arne Hennigsen. 2020. "Units of Measurement and the Inverse Hyperbolic Sine Transformation." The Econometrics Journal. doi: https://doi.org/10.1093/ectj/utaa032.

Betti, Gianni, Neil Dourmashkin, Mariacristina Rossi, and Ya Ping Yin. 2007. "Consumer Over-indebtedness in the EU: Measurement and Characteristics." Journal of Economic Studies 34(2):136-56. doi: 10.1108/01443580710745371.

Boen, Courtney, Lisa Keister, and Brian Aronson. 2020. "Beyond Net Worth: Racial Differences in Wealth Portfolios and Black-White Health Inequality across the Life Course." Journal of Health and Social Behavior 61(2):153-69. doi: $10.1177 / 0022146520924811$.

Brown, Sarah, and Karl Taylor. 2008. "Household Debt and Financial Assets: Evidence from Germany, Great Britain and the USA." Journal of the Royal Statistical Society: Series A (Statistics in Society) 171(3):615-43. doi: 10.1111/j.1467985X.2007.00531.x.

Cai, Yunchao, Selamah Abdullah Yusof, Ruzita Bt Mohd Amin, and Mohd Nahar Mohd Arshad. 2021. "The Multi-Dimensional Effect of Household Debt on Urban Individual Well-Being in Klang Valley Malaysia." Social Indicators Research 158(1):23-44. doi: 10.1007/s11205-021-02706-7.

Cleveland, William S. 1979. "Robust Locally Weighted Regression and Smoothing Scatterplots." Journal of the American Statistical Association 74(368):829-36. doi: 10.1080/01621459.1979.10481038.

Conger, Rand D., Katherine J. Conger, Glen H. Elder, Frederick O. Lorenz, Ronald L. Simons, and Les B. Whitbeck. 1992. "A Family Process Model of Economic Hardship and Adjustment of Early Adolescent Boys." Child Development 63(3):526. doi: 10.2307/1131344.

Conley, Dalton. 2001a. “A Room with a View or a Room of One's Own? Housing and Social Stratification.” Sociological Forum 16(2):263-80.

Conley, Dalton. 2001b. "Capital for College: Parental Assets and Postsecondary Schooling." Sociology of Education 74(1):59-72. doi: 10.2307/2673145.

Dew, Jeffrey. 2007. "Two Sides of the Same Coin? The Differing Roles of Assets and Consumer Debt in Marriage." Journal of Family and Economic Issues 28(1):89-104. doi: 10.1007/s10834-006-9051-6.

Duchon, Jean. 1977. "Splines Minimizing Rotation-Invariant Semi-Norms in Sobolev Spaces." Pp. 85-100 in Constructive Theory of Functions of Several Variables. Vol. 571, Lecture Notes in Mathematics, edited by W. Schempp and K. Zeller. Berlin, Heidelberg: Springer Berlin Heidelberg. 
Dwyer, Rachel E. 2018. "Credit, Debt, and Inequality." Annual Review of Sociology 44(1):237-61. doi: 10.1146/annurev-soc-060116-053420.

Fourcade, Marion, and Kieran Healy. 2013. "Classification Situations: Life-Chances in the Neoliberal Era." Accounting, Organizations and Society 38(8):559-72. doi: 10.1016/j.aos.2013.11.002.

Friedline, Terri, Rainier D. Masa, and Gina A. N. Chowa. 2015. "Transforming Wealth: Using the Inverse Hyperbolic Sine (IHS) and Splines to Predict Youth's Math Achievement." Social Science Research 49:264-87. doi: 10.1016/j.ssresearch.2014.08.018.

Gibson-Davis, Christina, and Heather D. Hill. 2021. "Childhood Wealth Inequality in the United States: Implications for Social Stratification and Well-Being." RSF: The Russell Sage Foundation Journal of the Social Sciences 7(3):1-26. doi: 10.7758/rsf.2021.7.3.01.

Grätz, Michael, and Øyvind N. Wiborg. 2020. "Reinforcing at the Top or Compensating at the Bottom? Family Background and Academic Performance in Germany, Norway, and the United States." European Sociological Review 36(3):381-94. doi: 10.1093/esr/jcz069.

Hällsten, Martin, and Fabian T. Pfeffer. 2017. "Grand Advantage: Family Wealth and Grandchildren's Educational Achievement in Sweden.” American Sociological Review 82(2):328-60. doi: 10.1177/0003122417695791.

Hällsten, Martin, and Max Thaning. 2018. "Multiple Dimensions of Social Background and Horizontal Educational Attainment in Sweden." Research in Social Stratification and Mobility 56:40-52. doi: 10.1016/J.RSSM.2018.06.005.

Hällsten, Martin, and Max Thaning. 2021. "Wealth as One of the 'Big Four' SES Dimensions in Intergenerational Transmissions." Social Forces soab080. doi: 10.1093/sf/soab080.

Hansen, Marianne Nordli, and Maren Toft. 2021. "Wealth Accumulation and Opportunity Hoarding: Class-Origin Wealth Gaps over a Quarter of a Century in a Scandinavian Country." American Sociological Review 86(4):603-38. doi: 10.1177/00031224211020012.

Hastie, Trevor, and Robert Tibshirani. 1999. Generalized Additive Models. Boca Raton, Fla: Chapman \& Hall/CRC.

Hastie, Trevor, Robert Tibshirani, and Jerome Friedman. 2009. The Elements of Statistical Learning. New York, NY: Springer New York.

Hiilamo, Aapo. 2020. "Debt Matters? Mental Wellbeing of Older Adults with Household Debt in England." SSM - Population Health 12:100658. doi: 10.1016/j.ssmph.2020.100658. 
Hochman, Oshrat, and Nora Skopek. 2013. "The Impact of Wealth on Subjective WellBeing: A Comparison of Three Welfare-State Regimes." Research in Social Stratification and Mobility 34:127-41.

Karagiannaki, Eleni. 2017. "The Effect of Parental Wealth on Children's Outcomes in Early Adulthood." The Journal of Economic Inequality 15(3):217-43. doi: 10.1007/s10888-017-9350-1.

Keister, Lisa A., and Stephanie Moller. 2000. "Wealth Inequality in the United States." Annual Review of Sociology 26(1):63-81. doi: 10.1146/annurev.soc.26.1.63.

Killewald, Alexandra, Fabian T. Pfeffer, and Jared N. Schachner. 2017. "Wealth Inequality and Accumulation." Annual Review of Sociology 43:379-404. doi: 10.1146/annurev-soc-060116-053331.

McCulloch, Charles E., S. R. Searle, and John M. Neuhaus. 2008. Generalized, Linear, and Mixed Models. 2nd ed. Hoboken, N.J: Wiley.

Miller, Portia, Tamara Podvysotska, Laura Betancur, and Elizabeth Votruba-Drzal. 2021. "Wealth and Child Development: Differences in Associations by Family Income and Developmental Stage." RSF: The Russell Sage Foundation Journal of the Social Sciences 7(3):154-74. doi: 10.7758/rsf.2021.7.3.07.

Morris, Tim P., Ian R. White, and Michael J. Crowther. 2019. "Using Simulation Studies to Evaluate Statistical Methods." Statistics in Medicine 38(11):20742102. doi: $10.1002 / \operatorname{sim} .8086$.

Müller, Nora, Klaus Pforr, and Oshrat Hochman. 2020. “The Non-Linear Relationship between Parental Wealth and Children's Post-Secondary Transitions in Germany." Soziale Welt 71(3).

Panel Survey of Income Dynamics. 2021. Public Use Dataset. Produced and Distributed by the by the Survey Research Center, Institute for Social Research, University of Michigan, Ann Arbor, MI.

Pence, Karen M. 2006. "The Role of Wealth Transformations: An Application to Estimating the Effect of Tax Incentives on Saving." Contributions to Economic Analysis \& Policy 5(1):1-24. doi: 10.2202/1538-0645.1430.

Pfeffer, Fabian T. 2018. "Growing Wealth Gaps in Education." Demography 55(3):1033-68. doi: 10.1007/s13524-018-0666-7.

Schneider, Daniel. 2011. "Wealth and the Marital Divide." American Journal of Sociology 117(2):627-67. doi: 10.1086/661594.

Skopek, Nora. 2015. Wealth as a Distict Dimension of Social Inequality. Bamberg: University of Bamberg Press. 
Spilerman, Seymour. 2000. "Wealth and Stratification Processes." Annual Review of Sociology 26:497-524. doi: 10.1146/annurev.soc.26.1.497.

Wagner, Sander, Diederik Boertien, and Mette Gørtz. 2020. "The Wealth of Parents: Trends Over Time in Assortative Mating Based on Parental Wealth." Demography. doi: 10.1007/s13524-020-00906-3.

Wiborg, Øyvind N. 2017. "Family Wealth and School Grades in Norway - Exploring How the Immediate and Extended Family's Wealth Matter for the Children's School Performance." Pp. 136-57 in Social Inequality Across the Generations - The Role of Compensation and Multiplication in Resource Accumulation., edited by J. Erola and E. Kilpi-Jakonen. Cheltenham, U.K./Northampton, MA: Edward Elgar Publishing.

Wood, Simon N. 2006. "Low-Rank Scale-Invariant Tensor Product Smooths for Generalized Additive Mixed Models." Biometrics 62(4):1025-36. doi: 10.1111/j.1541-0420.2006.00574.x.

Wood, Simon N. 2017. Generalized Additive Models: An Introduction with R. Second edition. Boca Raton: CRC Press/Taylor \& Francis Group.

Zhan, Min, and Michael Sherraden. 2011. "Assets and Liabilities, Educational Expectations, and Children's College Degree Attainment." Children and Youth Services Review 33(6):846-54. doi: 10.1016/j.childyouth.2010.12.006. 


\section{Tables}

Table 1: Evaluated combinations of methods, wealth measures, and specifications

\begin{tabular}{|c|c|c|c|c|}
\hline No. & $\begin{array}{l}\text { Wealth } \\
\text { measure }\end{array}$ & Method & Specification & Equation \\
\hline 1 & NW & GLM & linear & $Y=\beta_{0}+\beta_{1} * N W(I H S)+\varepsilon$ \\
\hline 2 & NW & GLM & categorical & $Y=\beta_{0}+\beta_{1} * N W($ Quintiles $)+\varepsilon$ \\
\hline 3 & NW & GLM & cubic & $Y=\beta_{0}+\beta_{1} * N W(I H S)+\beta_{2} * N W(I H S)^{2}+\beta_{3} * N W(I H S)^{3}+\varepsilon$ \\
\hline 4 & NW & GAM & undefined & $Y=f(N W(I H S))+\varepsilon$ \\
\hline 5 & GW & GLM & linear & $Y=\beta_{0}+\beta_{1} * G W(I H S)+\varepsilon$ \\
\hline 6 & GW & GLM & categorical & $Y=\beta_{0}+\beta_{1} * G W($ Quintiles $)+\varepsilon$ \\
\hline 7 & GW & GLM & cubic & $Y=\beta_{0}+\beta_{1} * G W(I H S)+\beta_{2} * G W(I H S)^{2}+\beta_{3} * G W(I H S)^{3}+\varepsilon$ \\
\hline 8 & GW & GAM & undefined & $Y=f(G W(I H S))+\varepsilon$ \\
\hline 9 & GW + Debt & GLM & linear & $Y=\beta_{0}+\beta_{1} * G W(I H S)+\beta_{2} * \operatorname{Debt}(I H S)+\varepsilon$ \\
\hline 10 & GW + Debt & GLM & categorical & $Y=\beta_{0}+\beta_{1} * G W($ Quintiles $)+\beta_{2} *$ Debt (Quintiles) $+\varepsilon$ \\
\hline 11 & $\mathrm{GW}+\mathrm{Debt}$ & GLM & cubic & $\begin{array}{c}Y=\beta_{0}+\beta_{1} * G W(I H S)+\beta_{2} * G W(I H S)^{2}+\beta_{3} * G W(I H S)^{3}+\beta_{4} * \operatorname{Debt}(I H S)+\beta_{5} * \operatorname{Debt}(I H S)^{2} \\
+\beta_{6} * \operatorname{Debt}(I H S)^{3}+\varepsilon\end{array}$ \\
\hline 12 & GW + Debt & GAM & undefined & $Y=f(G W(I H S))+f(\operatorname{Debt}(I H S))+\varepsilon$ \\
\hline 13 & GW * Debt & GLM & linear & $Y=\beta_{0}+\beta_{1} * G W(I H S)+\beta_{2} * \operatorname{Debt}(I H S)+\beta_{3} * G W(I H S) * \operatorname{Debt}(I H S)+\varepsilon$ \\
\hline 14 & GW * Debt & GLM & categorical & $Y=\beta_{0}+\beta_{1} * G W($ Quintiles $)+\beta_{2} *$ Debt $($ Quintiles $)+\beta_{3} * G W($ Quintiles $) *$ Debt $($ Quintiles $)+\varepsilon$ \\
\hline 15 & GW * Debt & GLM & cubic & $\begin{array}{rl}Y=\beta_{0}+\beta_{1} * & G W(I H S)+\beta_{2} * G W(I H S)^{2}+\beta_{3} * G W(I H S)^{3}+\beta_{4} * \operatorname{Debt}(I H S)+\beta_{5} * \operatorname{Debt}(I H S)^{2} \\
& +\beta_{6} * \operatorname{Debt}(I H S)^{3}+\beta_{7} * G W(I H S) * \operatorname{Debt}(I H S)+\beta_{8} * G W(I H S)^{2} * \operatorname{Debt}(I H S)+\beta_{9} \\
& * G W(I H S)^{3} * \operatorname{Debt}(I H S)+\beta_{10} * G W(I H S) * \operatorname{Debt}(I H S)^{2}+\beta_{11} * G W(I H S) \\
& * \operatorname{Debt}(I H S)^{3}+\beta_{12} * G W(I H S)^{2} * \operatorname{Debt}(I H S)^{2}+\beta_{13} * G W(I H S)^{3} * \operatorname{Debt}(I H S)^{2}+\beta_{14} \\
& * G W(I H S)^{2} * \operatorname{Debt}(I H S)^{3}+\beta_{15} * G W(I H S)^{3} * \operatorname{Debt}(I H S)^{3}+\varepsilon\end{array}$ \\
\hline 16 & GW * Debt & GAM & undefined & $Y=f(G W(I H S), \operatorname{Debt}(I H S))+\varepsilon$ \\
\hline
\end{tabular}

Note: GAM=Generalized additive model; GLM=Generalized linear model, GW=Gross wealth; IHS=Inverse hyperbolic sine; NW=Net worth. 
Table 2: Pseudo-R2 by method and outcome

\begin{tabular}{llllll}
\hline Method & $\begin{array}{l}\text { Wealth } \\
\text { measure }\end{array}$ & Specification & High school & $\begin{array}{l}\text { Some } \\
\text { College }\end{array}$ & $\begin{array}{l}\text { Bachelor's } \\
\text { degree }\end{array}$ \\
\hline GLM & NW & categorical & 6.78 & 8.35 & 11.32 \\
GLM & GW * Debt & categorical & 10.50 & 10.70 & 13.99 \\
GAM & NW & undefined & 6.38 & 8.49 & 12.25 \\
GAM & GW * Debt & undefined & 10.40 & 11.09 & 15.80 \\
\hline
\end{tabular}

Note: GAM=Generalized additive model; GLM=Generalized linear model, GW=Gross wealth; NW=Net Worth 


\section{Figures}

Figure 1. Joint distribution of gross wealth and debt (on IHS scale)

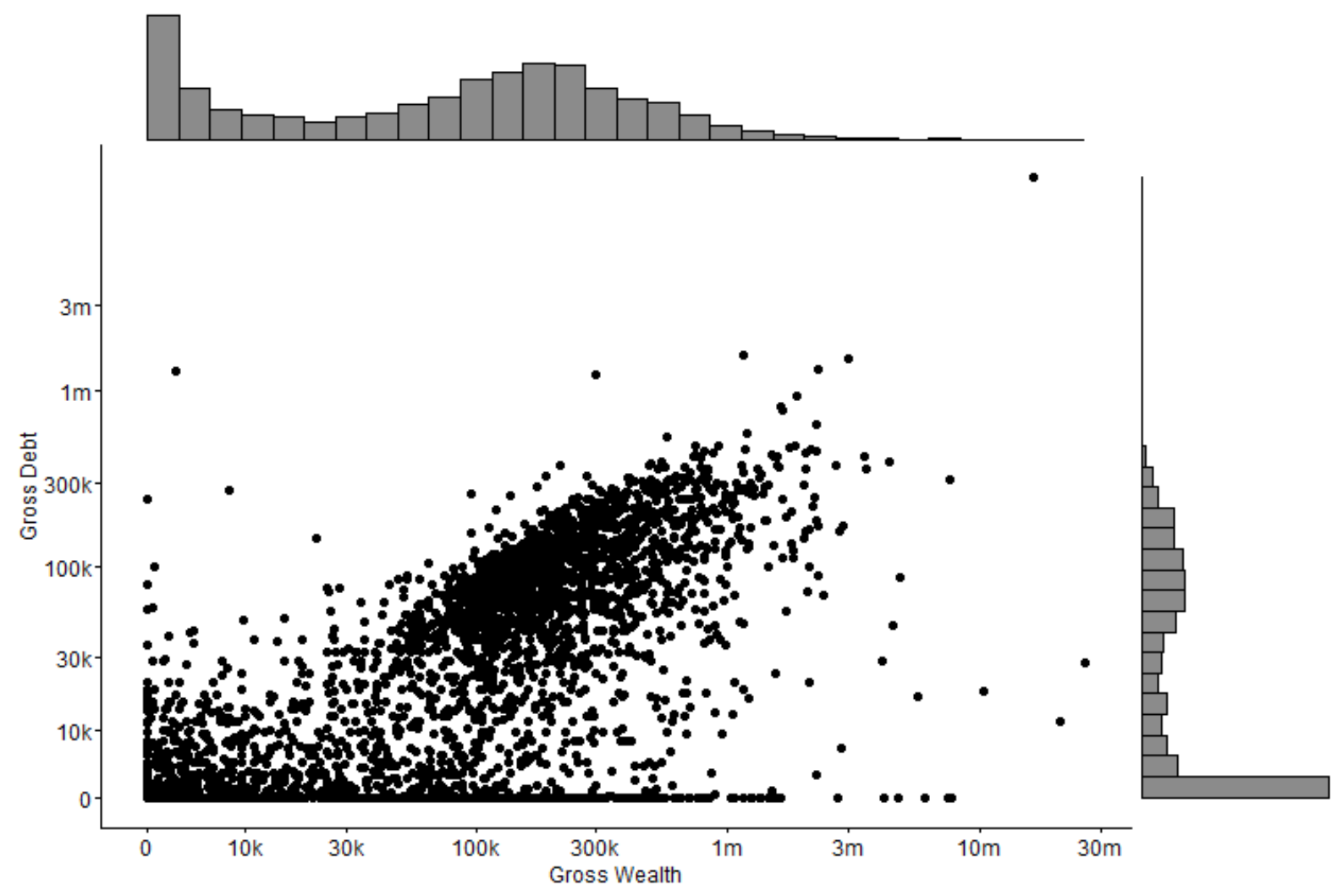

Note: Data of the Panel Survey of Income Dynamics; $\mathrm{N}=4,341$. 
Figure 2. MSEs of different combinations of methods, wealth measures, and specifications in the simulation analysis

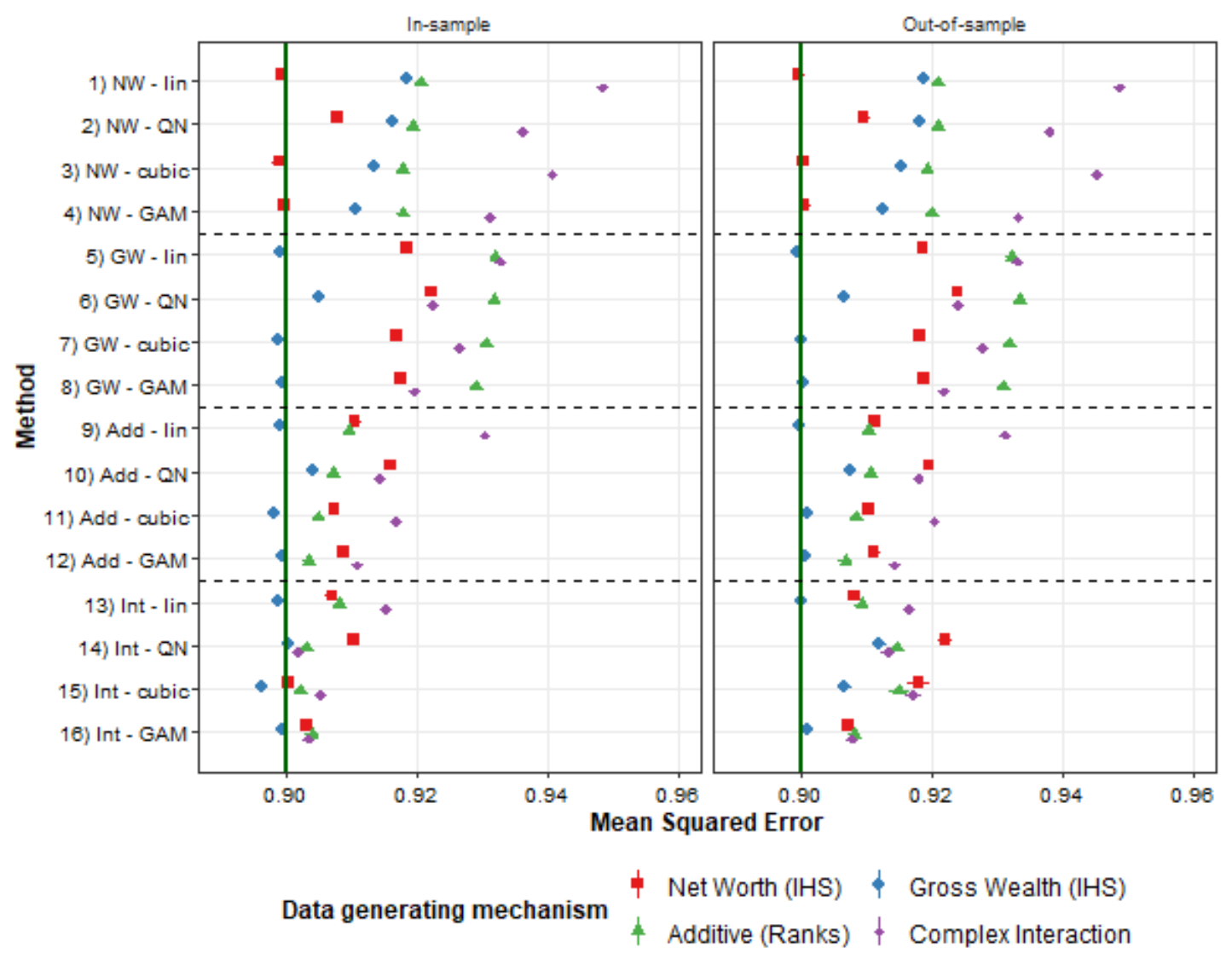

Note: Add.=Additive (Gross Wealth + Debt); GAM=Generalized additive model; GLM=Generalized linear model, GW=Gross wealth; IHS=Inverse hyperbolic sine; Int.=Interaction $($ Gross Wealth $\times$ Debt); lin=linear, NW=Net worth; $Q N=Q u i n t i l e$. 
Figure 3. Predicted probabilities of having graduated from high school at age 25 when using net worth quintiles vs. GAM with assets and debt
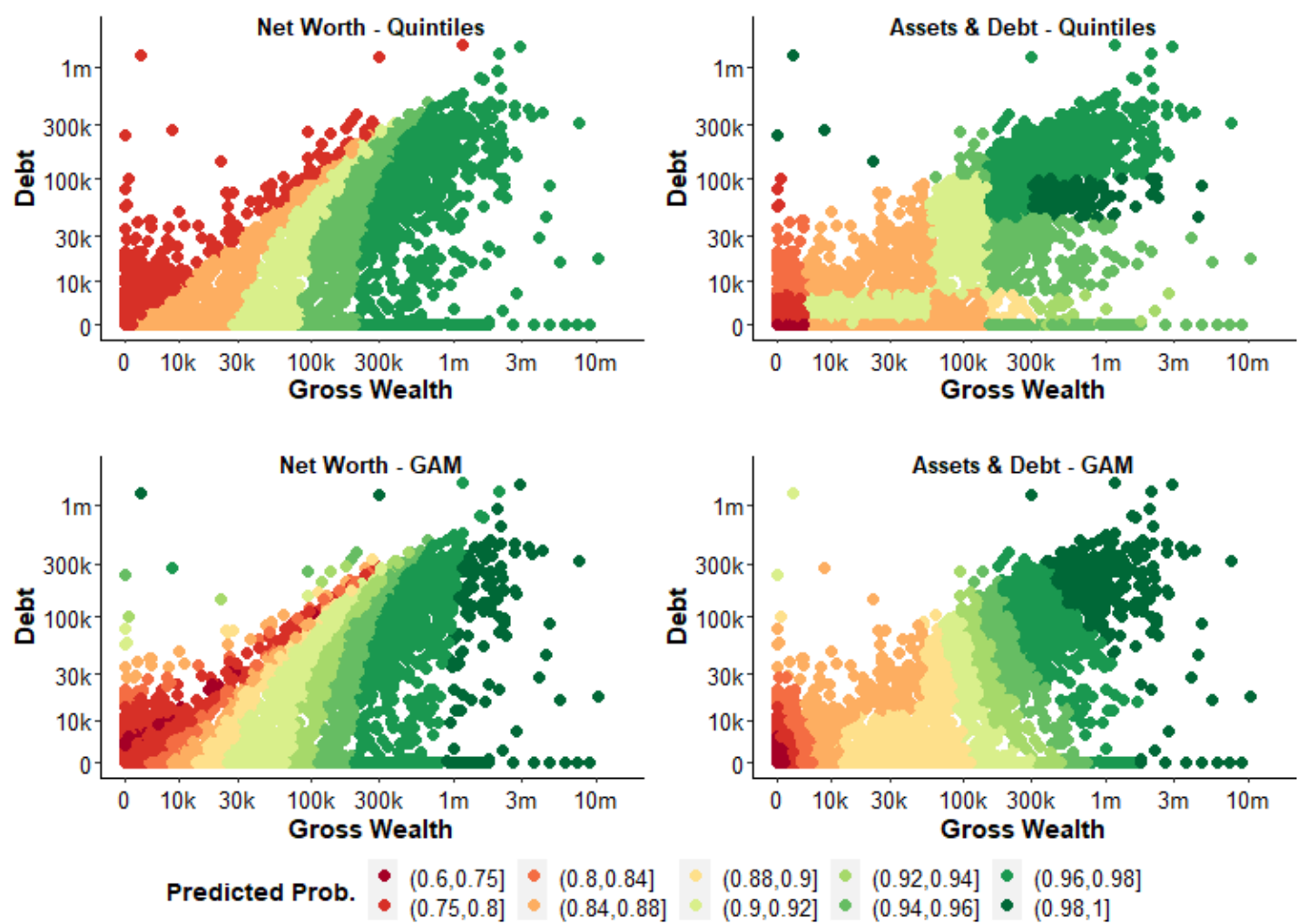

Note: Data of the Panel Survey of Income Dynamics; N=4,341. 
Figure 4. Predicted probabilities of having attended college at age 25 when using net worth quintiles vs. GAM with assets and debt
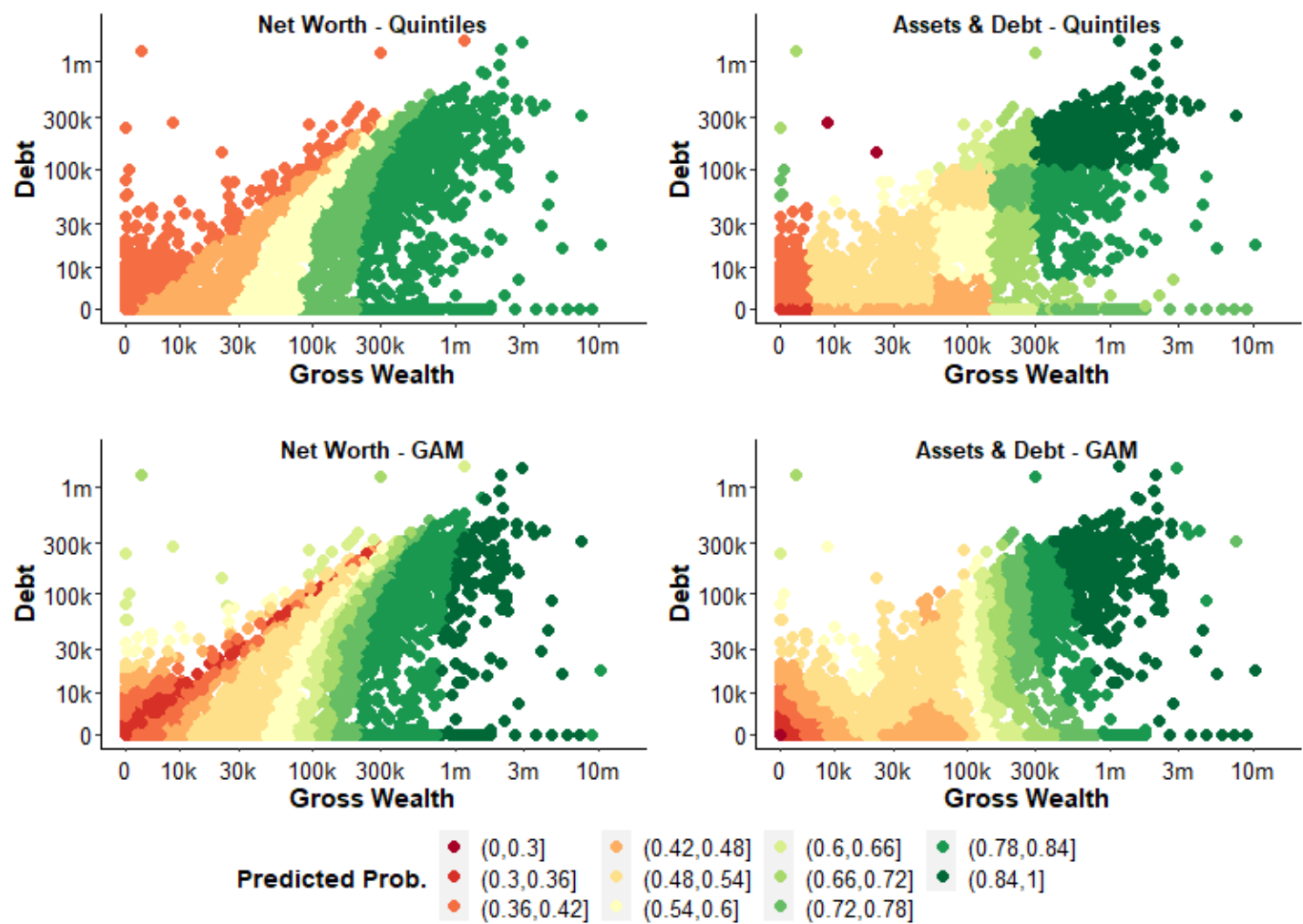

Note: Data of the Panel Survey of Income Dynamics; N=4,341. 
Figure 5. Predicted probabilities of having obtained a bachelor's degree at age 25 when using net worth quintiles vs. GAM with assets and debt
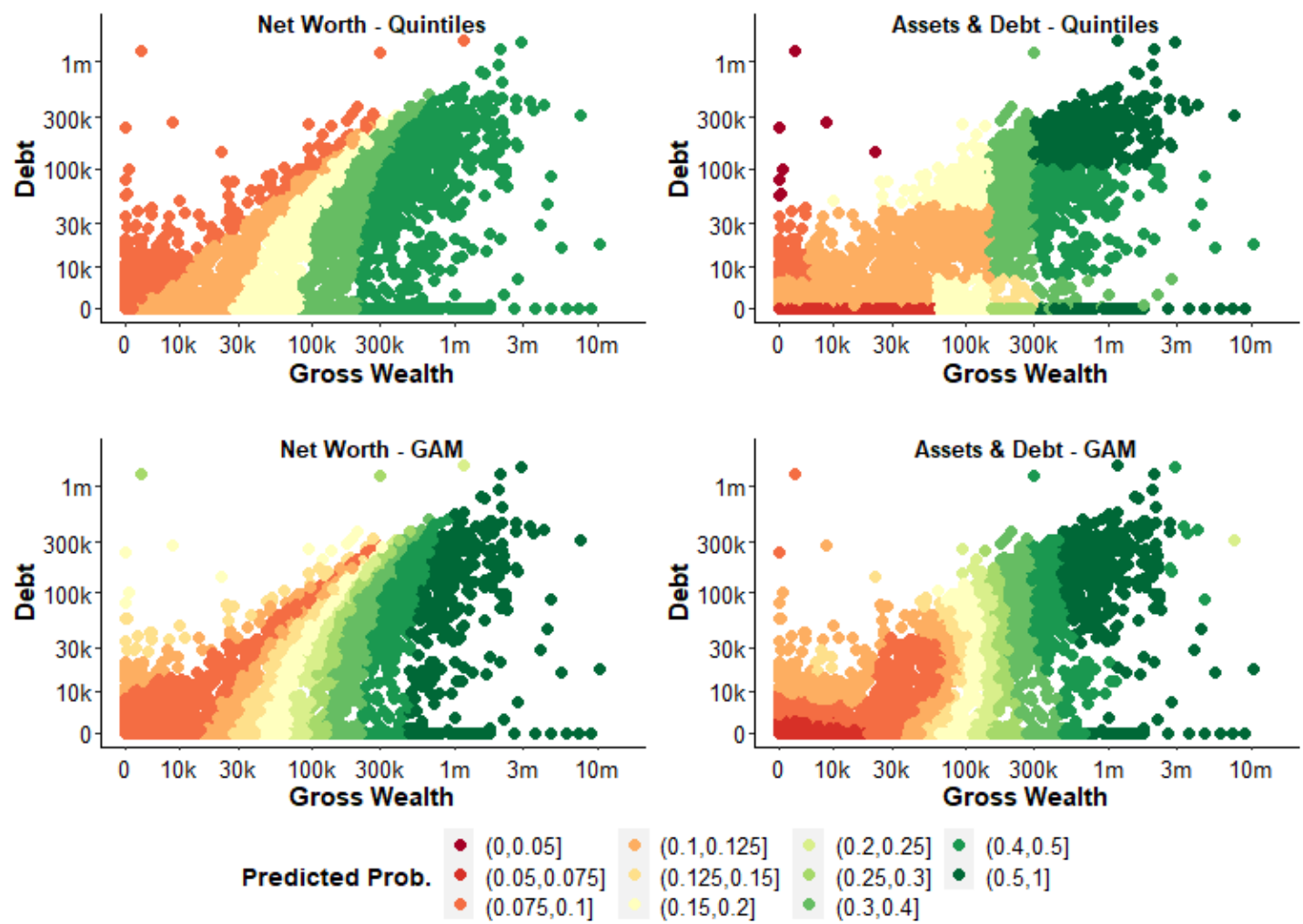

Note: Data of the Panel Survey of Income Dynamics; N=4,341. 


\section{Supplementary Materials}

\section{A. True values of $\mathrm{Y}$ in the simulation}

Figure A1. True values of Y by gross wealth and debt in the simulation analysis
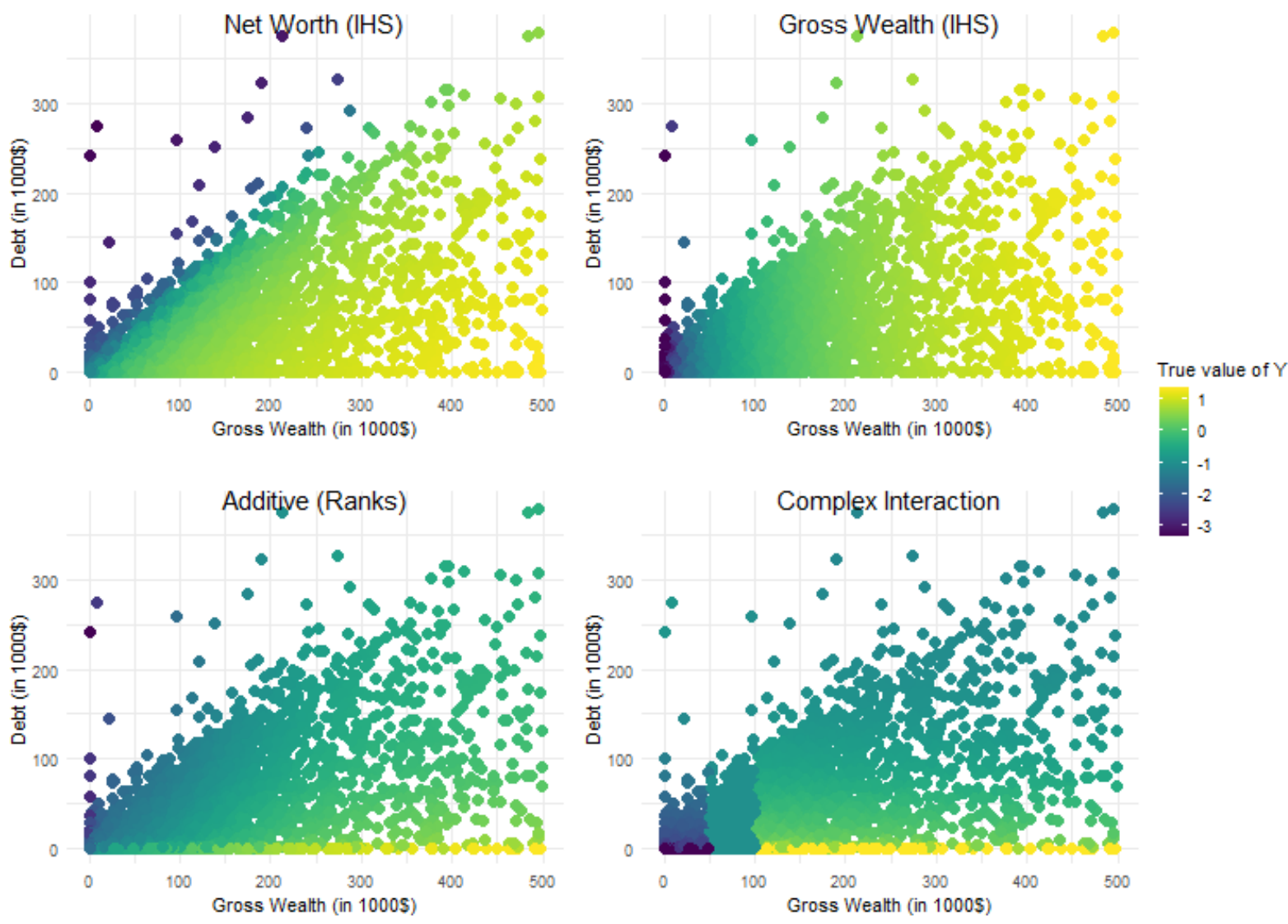


\section{B. Predicted probabilities for exemplary values}

Table B1. Predicted probability of having graduated from high school - based on GLM with net worth quintiles

\begin{tabular}{lll}
\hline & Predicted probability & Standard error \\
\hline 1. QN (-1562k; 1.4k] & 80.15 & 1.60 \\
2. QN (1.4k; 27.4k] & 87.98 & 1.19 \\
3. QN (27.4k; 80.8k] & 90.54 & 1.02 \\
4. QN (80.8k; 208.2k] & 94.62 & 0.72 \\
5. QN (208.2k; 25487k) & 97.39 & 0.46 \\
\hline
\end{tabular}

Table B2. Predicted probability of having graduated from high school - based on GAM (Net Worth)

\begin{tabular}{lll}
\hline & Predicted probability & Standard error \\
\hline$-100 \mathrm{k}$ & 92.87 & 4.20 \\
$-30 \mathrm{k}$ & 85.52 & 3.45 \\
$-10 \mathrm{k}$ & 77.00 & 2.73 \\
$-3 \mathrm{k}$ & 75.00 & 1.67 \\
0 & 76.48 & 1.34 \\
$3 \mathrm{k}$ & 79.47 & 1.25 \\
$10 \mathrm{k}$ & 86.15 & 1.24 \\
$30 \mathrm{k}$ & 90.35 & 0.96 \\
$100 \mathrm{k}$ & 93.53 & 0.70 \\
$300 \mathrm{k}$ & 96.70 & 0.57 \\
$1 \mathrm{~m}$ & 98.15 & 0.70 \\
$3 \mathrm{~m}$ & 99.15 & 0.78 \\
\hline
\end{tabular}

Table B3. Predicted probability of having graduated from high school - based on GLM with the interaction of gross wealth and debt

\begin{tabular}{l|lllll}
\hline \multirow{2}{*}{ Debt } & Gross Wealth & & & & \\
& $(0,4.8 \mathrm{k}]$ & $(4.8 \mathrm{k}$, & $(59.6 \mathrm{k}$, & $(149.1 \mathrm{k}$, & $(301.4 \mathrm{k}$, \\
& & $59.6 \mathrm{k}]$ & $149.1 \mathrm{k}]$ & $301,4 \mathrm{k}]$ & $26 \mathrm{~m}]$ \\
\hline$(103.8 \mathrm{k}, 16 \mathrm{~m})$ & 94.11 & 94.11 & 95.81 & 95.75 & 97.86 \\
& 3.50 & 3.50 & 2.68 & 1.60 & 0.69 \\
$(44.1 \mathrm{k}, 103.8 \mathrm{k}]$ & 81.43 & 83.92 & 92.27 & 96.48 & 98.71 \\
& 6.25 & 5.35 & 2.18 & 1.07 & 0.73 \\
$(7.1 \mathrm{k}, 44,1 \mathrm{k}]$ & 85.69 & 87.62 & 90.42 & 94.77 & 97.30 \\
& 2.68 & 2.68 & 2.07 & 1.42 & 1.17 \\
$(16,7.1 \mathrm{k}]$ & 87.77 & 90.48 & 88.33 & 88.23 & 92.32 \\
0 & 2.86 & 2.27 & 3.49 & 4.11 & 3.67 \\
& 73.15 & 82.05 & 86.95 & 92.97 & 92.63 \\
& 2.80 & 2.75 & 3.27 & 2.54 & 2.24 \\
\hline
\end{tabular}

Table B4. Predicted probability of having graduated from high school for exemplary values of gross wealth and debt - based on GAM (Gross Wealth, Debt).

\begin{tabular}{l|lllllll}
\hline \multirow{5}{*}{ Debt } & Gross & & & & & & \\
& Wealth & & & & & & \\
& 0 & $10 \mathrm{k}$ & $30 \mathrm{k}$ & $100 \mathrm{k}$ & $300 \mathrm{k}$ & $1 \mathrm{~m}$ & $3 \mathrm{~m}$ \\
\hline \multirow{4}{*}{$1 \mathrm{~m}$} & 94.01 & 89.24 & 88.89 & 95.34 & 98.49 & 99.39 & 99.6 \\
& $(8.73)$ & $(10.00)$ & $(8.92)$ & $(2.93)$ & $(0.93)$ & $(0.72)$ & $(0.93)$ \\
& 92.88 & 86.86 & 86.97 & 94.5 & 98.12 & 99.2 & 99.51 \\
& $(7.80)$ & $(9.27)$ & $(7.96)$ & $(2.53)$ & $(0.84)$ & $(0.66)$ & $(0.85)$ \\
\hline
\end{tabular}




\begin{tabular}{|c|c|c|c|c|c|c|c|}
\hline Debt & $\begin{array}{l}\text { Gross } \\
\text { Wealth } \\
0\end{array}$ & $10 \mathrm{k}$ & $30 \mathrm{k}$ & $100 \mathrm{k}$ & $300 \mathrm{k}$ & $1 \mathrm{~m}$ & $3 \mathrm{~m}$ \\
\hline $300 \mathrm{k}$ & $\begin{array}{l}91.04 \\
(6.82)\end{array}$ & $\begin{array}{l}84.88 \\
(7.49)\end{array}$ & $\begin{array}{l}85.5 \\
(6.08)\end{array}$ & $\begin{array}{l}93.39 \\
(1.92)\end{array}$ & $\begin{array}{l}97.62 \\
(0.66)\end{array}$ & $\begin{array}{l}98.84 \\
(0.61)\end{array}$ & $\begin{array}{l}99.3 \\
(0.81)\end{array}$ \\
\hline $100 \mathrm{k}$ & $\begin{array}{l}88.39 \\
(5.86)\end{array}$ & $\begin{array}{l}84.32 \\
(5.19)\end{array}$ & $\begin{array}{l}85.2 \\
(3.89)\end{array}$ & $\begin{array}{l}92.16 \\
(1.23)\end{array}$ & $\begin{array}{l}97.02 \\
(0.51)\end{array}$ & $\begin{array}{l}98.29 \\
(0.66)\end{array}$ & $\begin{array}{l}98.98 \\
(0.85)\end{array}$ \\
\hline 30k & $\begin{array}{l}83.63 \\
(4.67)\end{array}$ & $\begin{array}{l}85.47 \\
(3.01)\end{array}$ & $\begin{array}{l}86.36 \\
(2.28)\end{array}$ & $\begin{array}{l}91 \\
(1.06)\end{array}$ & $\begin{array}{l}95.78 \\
(0.70)\end{array}$ & $\begin{array}{l}97.59 \\
(0.98)\end{array}$ & $\begin{array}{l}98.72 \\
(0.98)\end{array}$ \\
\hline $10 \mathrm{k}$ & $\begin{array}{l}77.66 \\
(3.18)\end{array}$ & $\begin{array}{l}86.84 \\
(1.71)\end{array}$ & $\begin{array}{l}88.32 \\
(1.52)\end{array}$ & $\begin{array}{l}90.23 \\
(1.23)\end{array}$ & $\begin{array}{l}94.05 \\
(1.11)\end{array}$ & $\begin{array}{l}97.02 \\
(1.30)\end{array}$ & $\begin{array}{l}98.61 \\
(1.20)\end{array}$ \\
\hline 0 & $\begin{array}{l}70.04 \\
(1.90)\end{array}$ & $\begin{array}{l}87.3 \\
(1.71)\end{array}$ & $\begin{array}{l}89.61 \\
(1.62)\end{array}$ & $\begin{array}{l}89.64 \\
(1.78)\end{array}$ & $\begin{array}{l}91.71 \\
(2.04)\end{array}$ & $\begin{array}{l}96.81 \\
(1.80)\end{array}$ & $\begin{array}{l}98.75 \\
(1.39)\end{array}$ \\
\hline
\end{tabular}

Note. Grey cells indicate combinations of assets and debt with a density of less than $1 \%$ of the maximal density. Predicted values for these combinations are based on extrapolations. 


\section{Underlying regression coefficients and smoothing parameters}

Table C1. Regression coefficients of the GLMs and smooth parameters of GAMs for high school graduation

\begin{tabular}{|c|c|c|c|c|}
\hline \multicolumn{2}{|c|}{$\begin{array}{c}\text { GLM NW } \\
\text { Regression coefficient (standard errors) }\end{array}$} & GLM Interaction & \multicolumn{2}{|l|}{ GM Interaction } \\
\hline Regression coefficient ( & & & & \\
\hline NW 2.QN & $0.826^{* * * *}(0.129)$ & - & - & - \\
\hline NW 3.QN & $1.171^{* * * *}(0.141)$ & - & - & - \\
\hline NW 4.QN & $1.850^{* * *}(0.175)$ & - & - & - \\
\hline NW 5.QN & $2.415^{* * * *}(0.218)$ & - & - & - \\
\hline GW 2.QN & - & $1.039^{* * *}(0.202)$ & - & - \\
\hline GW 3.QN & - & $0.889^{* * * *}(0.284)$ & - & - \\
\hline GW 4.QN & - & $1.910^{* * * *}(0.601)$ & - & - \\
\hline GW 5.QN & - & $1.939^{* * * *}(0.522)$ & - & - \\
\hline Debt 2.QN & - & $0.359^{*}(0.195)$ & - & - \\
\hline Debt 3.QN & - & $0.528^{*}(0.301)$ & - & - \\
\hline Debt 4.QN & - & $0.175(1.158)$ & - & - \\
\hline Debt 5.QN & - & $12.643(309.120)$ & - & - \\
\hline GW 2.QN * Debt 2.QN & - & $-0.063(0.339)$ & - & - \\
\hline GW 3.QN * Debt 2.QN & - & $-0.187(0.463)$ & - & - \\
\hline GW 4.QN * Debt 2.QN & - & $-1.177(0.821)$ & - & - \\
\hline GW 5.QN * Debt 2.QN & - & $-0.695(0.918)$ & - & - \\
\hline GW 2.QN * Debt 3.QN & - & $-0.573(0.395)$ & - & - \\
\hline GW 3.QN * Debt 3.QN & - & $-0.097(0.457)$ & - & - \\
\hline GW 4.QN * Debt 3.QN & - & $-0.365(0.758)$ & - & - \\
\hline GW 5.QN * Debt 3.QN & - & $-0.222(0.784)$ & - & - \\
\hline GW 2.QN * Debt 4.QN & - & $-0.228(1.289)$ & - & - \\
\hline GW 3.QN * Debt 4.QN & - & $0.244(1.202)$ & - & - \\
\hline GW 4.QN * Debt 4.QN & - & $0.399(1.341)$ & - & - \\
\hline GW 5.QN * Debt 4.QN & - & $1.326(1.453)$ & - & - \\
\hline
\end{tabular}




\begin{tabular}{|c|c|c|c|c|}
\hline GW 2.QN * Debt 5.QN & - & $-1.039(437.161)$ & - & - \\
\hline GW 3.QN * Debt 5.QN & - & $-11.662(309.120)$ & - & - \\
\hline GW 4.QN * Debt 5.QN & - & $-12.207(309.121)$ & - & - \\
\hline GW 5.QN * Debt 5.QN & - & $-11.692(309.120)$ & - & - \\
\hline Intercept & $1.103^{* * *}(0.078)$ & $0.923^{* * *}(0.091)$ & $2.365 * * *(0.064)$ & $2.384 * * *(0.099)$ \\
\hline \multicolumn{5}{|c|}{ Effective degrees of freedom of the smooth terms $\left(\chi^{2}\right.$ of the smooth terms) } \\
\hline NW & - & - & $5.632 * * *(210.9)$ & - \\
\hline GW & - & - & - & $2.925 * * *(38.076)$ \\
\hline Debt & - & - & - & $1.001 *(6.475)$ \\
\hline GW * Debt & - & - & - & $5.094(13.238)$ \\
\hline
\end{tabular}

Note: GAM=Generalized additive model; GLM=Generalized linear model, GW=Gross Wealth, NW=Net Worth. Data of the Panel Survey of Income Dynamics; $\mathrm{N}=4,341$. Significance Levels: $* * * \mathrm{p}<0.001 ; * * \mathrm{p}<0.01 ; * \mathrm{p}<0.05$. Standard erros of regression coefficients in paratheses. 


\section{Adjusted wealth gaps}

Figure D1. Predicted probabilities of having graduated from high school at age 25 when using net worth quintiles vs. GAM with assets and debt, adjusted for control variables.
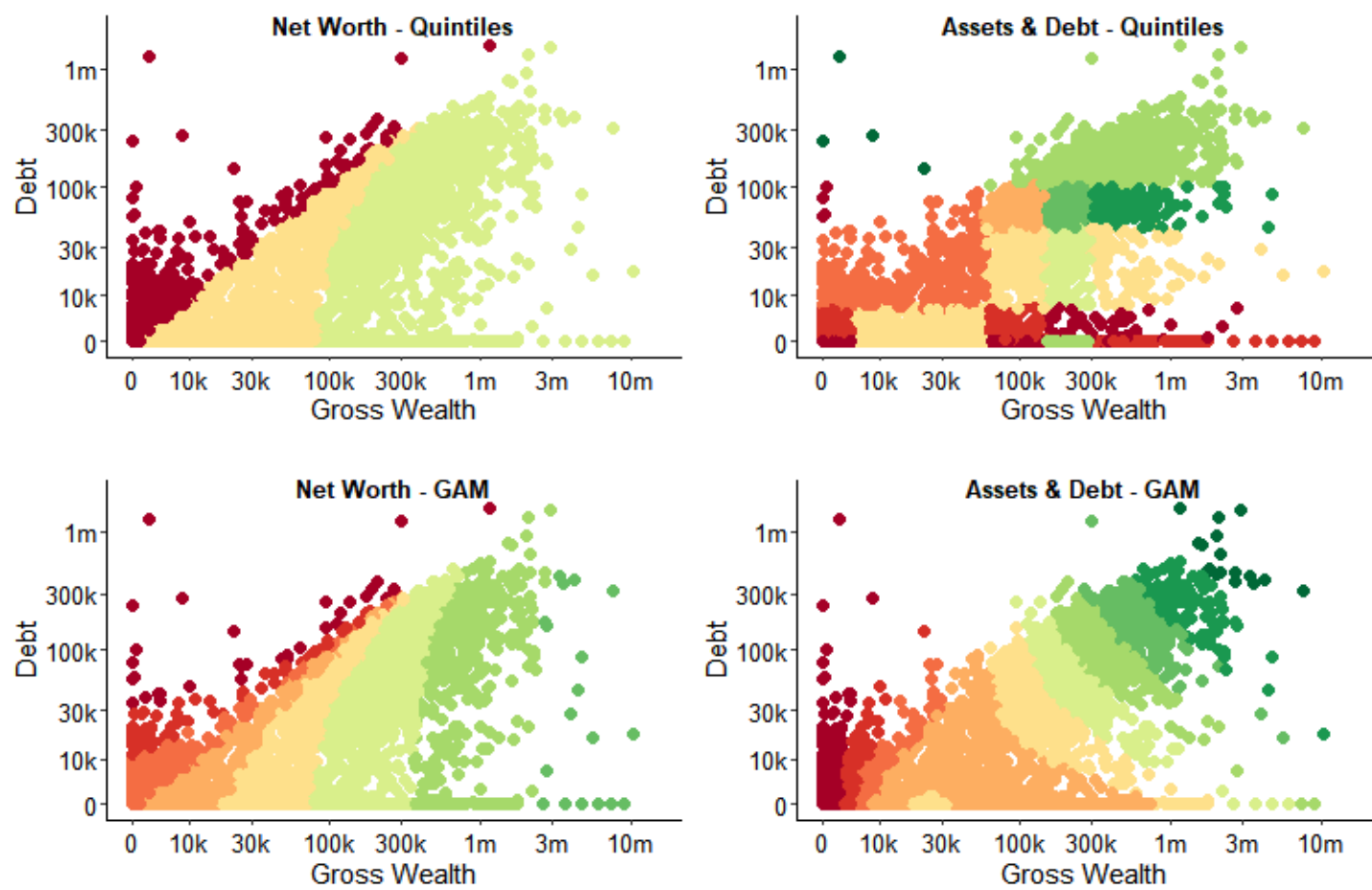

Predicted probability $\bullet(0,0.9]-(0.91,0.92]$

$(0.93,0.94] \bullet(0.95,0.96] \bullet(0.97,0.98]$

$(0.94,0.95] \cdot(0.96,0.97] \bullet(0.98,1]$

Note: Data of the Panel Survey of Income Dynamics; $\mathrm{N}=4,341$. 
Figure D2. Predicted probabilities of having attended college at age 25 when using net worth quintiles vs. GAM with assets and debt, adjusted for control variables.
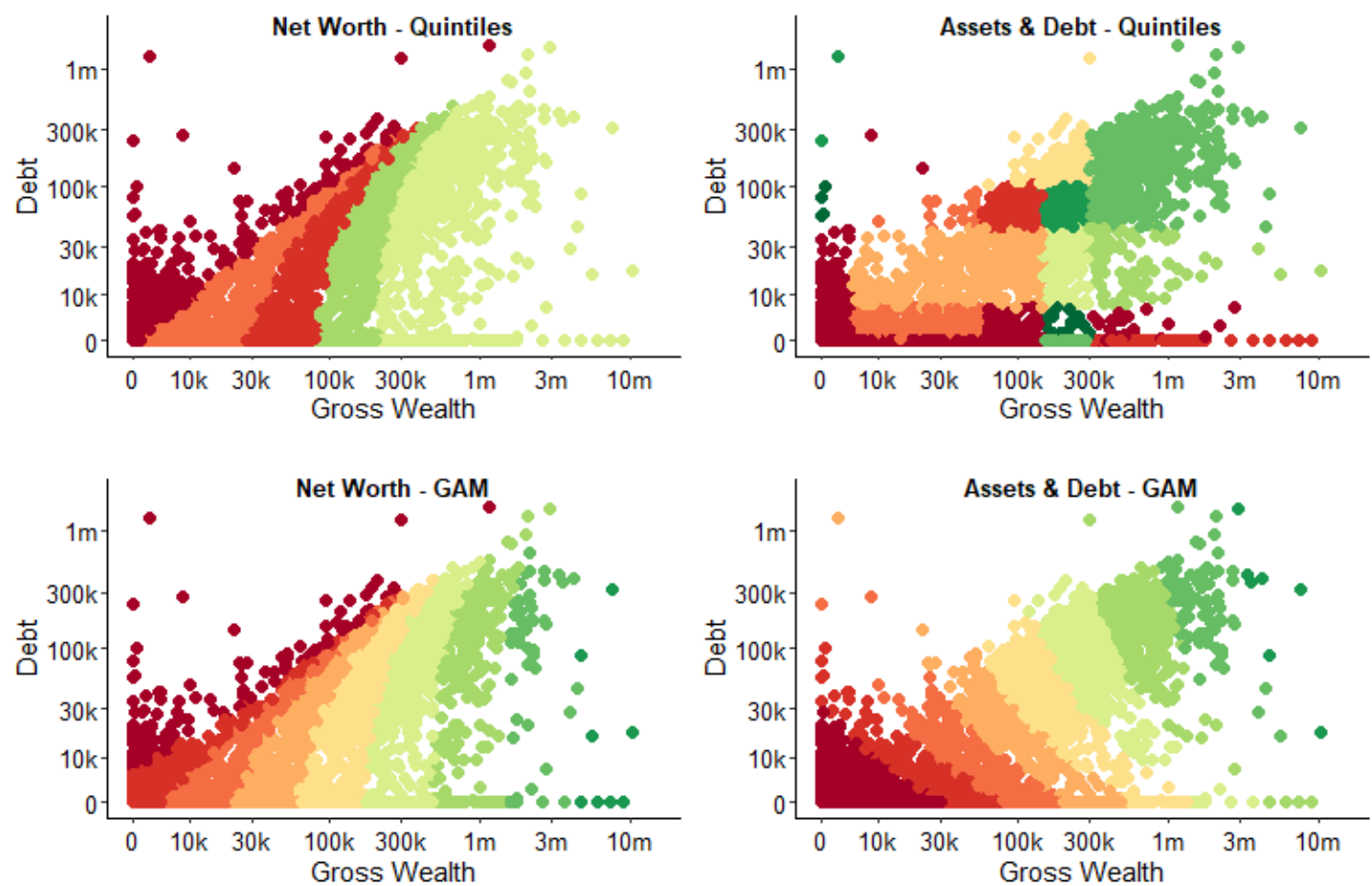

Predicted probability $\begin{aligned} & \bullet(0,0.52] \\ & \bullet\end{aligned}$

$(0.58,0.6] \bullet(0.62,0.64] \bullet(0.66,0.68]$

$(0.6,0.62] \cdot(0.64,0.66] \bullet(0.68,1]$

Note: Data of the Panel Survey of Income Dynamics; N=4,341. 
Figure D3. Predicted probabilities of having obtained a bachelor's degree at age 25 when using net worth quintiles vs. GAM with assets and debt, adjusted for control variables.
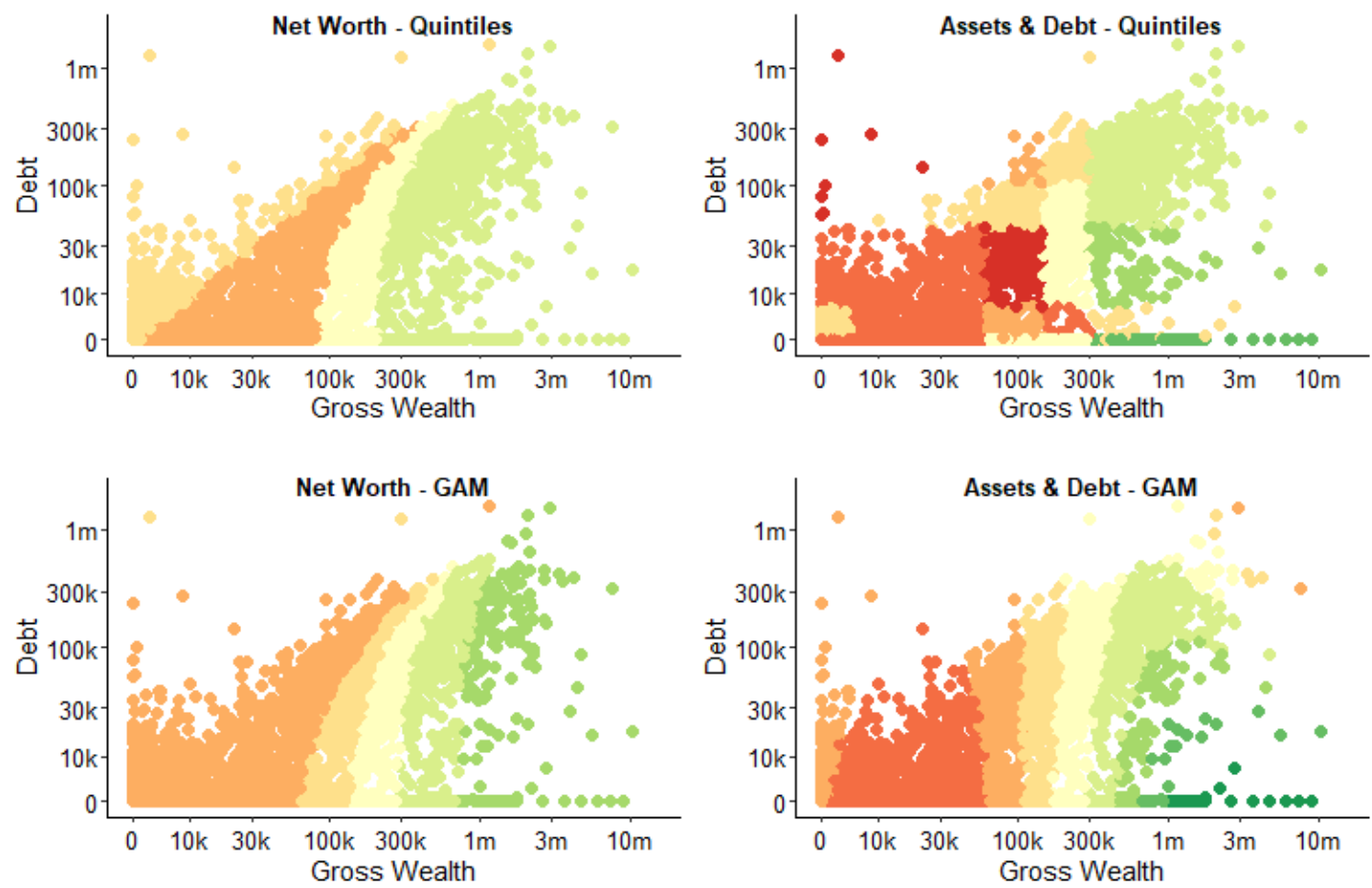

Predicted probability $-(0,0.06]$

$\begin{array}{lll}(0.08,0.1] & (0.12,0.14] & (0.16,0.18] \\ (0.1,0.12] & (0.14,0.16] & -(0.18,0.2]\end{array}$

Note: Data of the Panel Survey of Income Dynamics; $\mathrm{N}=4,341$. 